\title{
Peep Show: The Lamentations of Justyna Bargielska
}

\author{
Adam Lipszyc
}




\section{Peep Show: The Lamentations of Justyna Bargielska}

DOI:10.18317/td.2018.en.1.9

We had children, yet they were not children, but shoes for the day

I'm not leaving you, shoes, just moving on. Justyna Bargielska, Dwa fiaty [Two fiats]

Do not read gediotayikh [thy kids] but geviotayikh [thy corpses] Eichah (Lamentations) Rabbah

Melanie Klein taught us that the affect of mourning is fundamental in determining our relationship to the world. According to her theory, already a classic in the field, every individual occupies the paranoid-schizoid and depressive positions successively; the two positions being defined by the subject's relations with the primal object, that is, the mother's breast. ${ }^{1}$ In the paranoidschizoid position, the infant treats the breast that delivers satisfaction and the breast that brings frustration as two separate objects. The infant is subject to fantasies of omnipotence, which present the good breast as entirely obedient to them, and the bad one as something

1 See Melanie Klein "Some Theoretical Conclusions Regarding the Emotional Life of the Infant," in Envy and Gratitude (London: Vintage, 1997), 61-93.
This text came about within a project financed by the Polish National Science Centre from funds granted on the basis of decision no. DEC2011/03/B/HS2/05729

\section{Adam Lipszyc}

- essayist and translator, he works at the Institute of Philosophy and Sociology of the Polish Academy of Sciences, lectures at the Graduate School for Social Research, Collegium Civitas, and the Franz Kafka Universität Muri bei Bern. He investigates the intersections of philosophy, theology, and literature. He was awarded the Andrzej Siemek Prize by Literatura na Świecie, the Allianz Kulturstiftung prize, and the Gdynia Literary Prize. Contact: adamlipszyc@gmail. com 
that can be wrecked at will. The young subject is, in fact, unable to differentiate himself from the external world, confusing internal representations of objects with external ones: manipulating representations is confused with the operations on the things themselves. The subsequent transition to the depressive position is accompanied by several fundamental changes in subject-world relations. The good and bad breasts are recognised as one and the same, which in addition shows itself to be external, and painfully so, as it is beyond the subject's control. Internal objects succumb to disintegration, and the subject wallows in mourning after the loss of that which is most precious, a loss he believes he has caused thorough his own aggressive behaviour towards the breast. The arduous, never-ending process of reparation engenders a provisional awareness of the existence of good objects and reconstructs their inner representations, which are now no longer confused with what they represent. According to Klein, the successful transition through this first and inevitable depression produces in us mechanisms that crucially come into play during subsequent experiences of loss defining human life. Hanna Segal, Klein's student and codifier of Klein's work, argues that the process of reparation, in fact, makes it possible for linguistic representation and proper thinking to emerge. ${ }^{2}$ The thoughts and words found in the psyche's internal "container" symbolise external objects, yet retain within themselves mournful self-knowledge about our non-identity with these objects, and the fact that these objects are already in a way lost because of their very externality and independence from our will. There is no thought or speech without the affect of mourning.

This is a beautiful and evocative vision. At the same time, though, it is hard to escape the sense that it is dogged by serious limitations. One of these is that loss is conceived here in extremely narrow terms, and from only one, very specific perspective. If we stick to this theory, we are looking at loss from the angle of a fragile, dependent individual who must become independent and reconcile, albeit provisionally, with being separated from that which gives him a sense of bliss. Yet these tools in an unaltered form do not allow us to describe the loss experienced by the other side - the mother herself. This is all the more peculiar as the intellectual framework and images that orient Klein's conceptions sometimes seem to suggest the opposite approach to loss. In this respect, what might be particularly interesting is a specific circumstance related to Klein's spatial imagination. Although for her, the fundamental problem is the separation of the becoming subject from the caring and satisfying object whose presence perhaps reproduces an image of some primal, narcissistic fullness before birth; Klein by no means invokes images

2 See Hanna Segal, Dream, Phantasy and Art (New York: Routledge, 1991). 
of an external container that might symbolise the mother's womb, a blissful space in which the subject would place himself in his phantasies. The essential reference point here is in fact the breast, an object that is partly incorporated by the infant itself, filling it with milk, and represented and duplicated by an internal object which is located in the inner container of the psyche and initially confused with the external object. In other words, Klein and Segal's use of the image of the container and what it holds might suggest grasping loss from exactly the opposite perspective to that which the two theoreticians represent: the perspective of the mother, and not the child. However, they do not commit themselves to such a reversal which, after all, seems essential if we wish to achieve a fuller understanding of the affect of mourning, and is certainly essential for the primary aim of our deliberations, which is to interpret several of Justyna Bargielska's texts. This is why, while bearing in mind the key link established by Klein and Segal between thinking, language, and mourning and the evocative image of the internal "container," we must now leave behind their perspective and look elsewhere for help. For the sake of employing an interdisciplinary approach, I propose examining in turn two works from two quite different fields.

The first of these is the work by anthropologist Galit Hasan-Rokem entitled Web of Life: Folklore and Midrash in Rabbinic Literature. ${ }^{3}$ The Israeli author analyses a set of Midrashim known as Eichah Rabbah, the collection of exegetic reflections and parables revolving around the Book of Lamentations. In an unpretentious and yet extremely productive way, her book embodies the idea of irreligiously appropriating, assimilating, and exploiting certain important fragments from the corpus of canonical writings of a religious tradition. The essential methodological idea of the book - one that I do not feel competent to judge - is as follows: as with other collections of Midrashim, Eichah Rabbah is full of material drawn not from the high culture of rabbinic academies, but folk culture: there are a number of parables also known from other cultures, a great deal of intentional and unintentional description of customs, numerous anecdotes, and riddles. Hasan-Rokem suggests that by including this material the editors of the text opened it to many intellectual elements originating from the layers of culture and society which are not usually recorded. The task of an anthropological reader would therefore be to extract these elements and lend them a voice, which often conflicts with the voice of rabbinical ideology that dominates the text.

Eichah Rabbah seems to be a particularly rewarding object of this kind of deconstructive analyses owing to the central topic that these Midrashim of the

3 Galit Hasan-Rokem, Web of Life: Folklore and Midrash in Rabbinic Literature, trans. Batya Stein (Stanford: Stanford University Press, 2000). Hereafter WL, with the page number. 
Book of Lamentations comment on: the destruction of the Temple and expulsion of the nation of Israel. The texts revolve around the most human issues of loss and grief, which is why the national and theological perspectives intertwine time and again, sometimes conflicting with a perspective that is quite personal and existential, and handled in a way that is not always in accordance with the rabbinical approach. In particular, Hasan-Rokem juxtaposes two takes on loss which clash in Eichah Rabbah. The first perspective, attributed to the rabbinical line, is related to theodicy and the idea of retribution: this point of view sees loss as an understandable retribution from a cruel yet just God for the sins that have been committed. The second perspective is concealed in the word eichah (how), the first word of the Book of Lamentations, which expresses the wonder and despair at utterly incomprehensible and inconceivable loss. The author writes:

Folk narratives are a powerful instrument for offering a valid spiritual alternative to the doctrine of retribution as an interpretation of the historical plight of the times. Anonymity and the collective character of folk literature, together with its capacity to allow expression to "other," nonelitist groups, turn it into a convenient instrument for conveying feelings and opinions that are not necessarily compatible with ideological trends dominant in the textual establishment of rabbinic literature. (WL, 45)

Hasan-Rokem develops this juxtaposition by brilliantly combining it with an analysis of verbal forms of expression, thereby sketching a productive conception of the link between language and the affect of mourning. She notes that Eichah Rabbah contains a collection of riddles that are thematically only loosely connected to the main theme of the book. Her argument is that this should not be seen as an editorial error; rather, the very figure of the riddle, or mystery, is directly connected to the fundamental subject of these meditations and parables, that is to questions concerning unintelligible, mysterious loss that cannot be accounted for by calculations of retribution or even by the most sophisticated kind of theodicy. Incidentally, the author is not entirely consistent as she in fact proposes two different angles: on the one hand, she simply contrasts systems of retribution with the riddle; on the other hand, especially in the beautiful epilogue, she categorises the "riddle," conceived of as a verbal construction referring to a specific solution, as a type of calculation under the heading of retribution ideology, whereas the structure which resists such calculations is now identified as "enigma" devoid of any solution. In any case, the main idea is clear: the structure of theodicy and retribution is broken up by the mysterious and enigmatic nature of loss. As Hasan-Rokem writes, 
It is exactly the presence of riddle tales and other genres of folk literature that makes it impossible for rabbinic literature to barricade itself behind the safety of uniform and authoritative conventions, creating a pervasively skeptical subversion against a potentially totalitarian monotheism. (WL, 52)

And further:

In the riddle tales in Lamentations Rabbah, the loss assumes form in pictures, images, and plots. The theme of loss fits the inner nature, I would even say, the logical nature, of the riddle. (WL, 65)

In the next part of this passage, Hasan-Rokem explains that the local, fragmentary nature of a riddle, as well as the fact that it has a solution in the end, brings some comfort. Yet, she also notes that the contrast with the insoluble riddle of loss remains all the greater - thus making "enigma" an even more appropriate expression. The entire matter is therefore summed up best by the following:

The religious answer is engaged in an effort to breathe meaning into the loss, and to make it part of a vision of the world as an ordered entity that obeys certain laws, and can be predicted and justified. [...] Yet Lamentations Rabbah is also a text in which loss becomes an independent existential entity that breaks free of logic, as the lasting enigma escapes the boundaries of the solved riddle. The poetic imagery allows loss, as it were, to speak in its own language. (WL, 62)

Hasan-Rokem makes this strife between the ideology of retribution and the enigma of loss relevant to the very structure of the written text. According to the kabbalistic conception, the text of the Torah is only a commentary, the "oral Torah" which is to expound the mystical "written Torah." Put in another way, we do not have the actual text of revelation, or, according to one of the more eccentric views, we can find it in the form of the empty spaces between the lines. Perhaps in referring to this image, and also artfully intercepting it, Hasan-Rokem seems to identify the written Torah with places of enigmatic logical breakdowns, places which create a space for expressing the most personal of sufferings: a splendid paradox would be that the true book of revelation would be found in elements drawn from oral culture, internally broken and breaking the structure of the written text. The author writes:

Eichah Rabbah is an exegetic Midrash. Its order is thus dictated by the order of the verses in the Book of Lamentations. But the verses are like rungs 
in a ladder, and those who climb from rung to rung pause in the empty spaces between, which are flooded by turbulence, irrationality, and, at times, the unexpected. Between the verses, the Midrash is not committed to any law. (WL, 63)

The conflict between retributive calculations, the law, and the structure of the text, as well as moments of subversion expressing loss, is also connected to the conflict between the patriarchal perspective and that of women. Women would in fact be one of those non-elite groups that find voice in the folk elements of rabbinic literature, and Eichah Rabbah would be a notable text since the theme of loss and mourning naturally opens it to images of women lamenting their dead. Hasan-Rokem's schematic view portrays men from the text of Eichah Rabbah as tending towards retributive calculations, the ideology of martyrdom, aggression and an incapacity for lamentation, while portraying women as being able to cope with the enigmatic nature of loss as well as being able to grieve. According to the author, the following, truly singular tale told in Eichah Rabbah demonstrates several key elements in this comparison: 1) the subversive and dangerous power of excessive despair, which undermines the patriarchal order of retributive calculation; 2) the ability to lament, i.e. mourning for the dead without framing loss in the context of theodicy; and 3) the significant fact that invoking a female figure often shifts the text of the Midrash from the level of national and theological discourse to that of the most personal loss.

A woman living in the neighborhood of R. Gamaliel had a son, a young man who died, and for whom she would weep at night. On hearing her, R. Gamaliel was reminded of the destruction of the Temple, and he wept until his lashes fell out. When his disciples noticed this, they removed her from his neighbourhood. (WL, 137)

What is most important for our consideration, however, is the fact that the inclusion of the female perspective, almost in passing, causes a fundamental shift in perspective within the problematic of loss and mourning - a move away from that of the infant to that of the mother - which I mentioned when referring to the limitations of Klein's and Segal's conceptual framework. If, in theological terms, the Kleinian perspective would be the perspective of a man abandoned by God and weaned off the great breast called the Temple, then in Eichah Rabbah, this vantage point is accompanied by the perspective of a parent grieving for a lost child. Specifically, the mourner is God himself. He appears here several times as an impetuous father, who in a fit of wrath has killed his son, and is now trying to mourn him. In one of the best-known 
and most astonishing passages of the book (in which God in fact is not saddled with direct responsibility for a catastrophe that has befallen Israel), God asks the angels what an earthly king does when he grieves for someone in other words, God is painstakingly learning the process of mourning from humans (WL, 136-137). However, if we are to follow Hasan-Rokem's argument and accept that lamentation is above all a hallmark of women, then God should really learn this craft from a queen rather than a king and, at least for a moment, become a woman. Indeed in Eichah Rabbah, this nearly (just nearly!) comes to pass, as it is in this book that for the first time, almost (just almost!) unequivocally, the traditional term of Shekhinah is used to refer to the personification of a female aspect of God - and it is in this sense that the term will go on to enjoy great success in the kabbalistic tradition. Here, then, is God himself well-nigh becoming Rachel weeping for her children (WL, 128).

Let us move now onto a book by another author analysing a different tradition entirely. What I have in mind is a relatively slim, but very rich book Mothers in Mourning by Nicole Loraux, the French student of ancient Greek culture. ${ }^{4}$ Its main subject is the relationship between women's lamentational practices and the political order in democratic Athens; the central thesis is the assertion that there is an insoluble conflict between them. Like Hasan-Rokem, who asserts that the female moment of the enigmatic eichah (a lament that does not accept any calculations and mourns loss's insurmountable separation) was capable of questioning the patriarchal order of the rabbinical text, Loraux maintains that the Greek political order had to employ legal regulations to defend itself from mothers in mourning. "Passion in the city-state? Páthos affecting the citizens? Danger" (MM, 9). This is why mothers in mourning were not permitted to lament on the streets; they were to remain locked up in the private sphere.

Considering the relationship between female mourning and the democratic order of Athenian politics, Loraux points out that one can speak of a conflict between two types of memory. If the polis is a community commemorating its own laws, institutions and customs, and if (as in Pericles' famous funeral speech) in remembering its sons that have perished in heroic battle the city remembers itself above all, and maintains its continuity through the ages, then the distinct but equally persistent motherly memory of mourning continually tears this continuity apart and opposes the latter, not allowing itself to disappear into some order of generality, all the while moving inexorably towards grieving, unforgiving wrath, namely, menis. This first word of Homer's Iliad refers, of course, to the anger of Achilles. However, Loraux notes that the same

4 Nicole Loraux, Mothers in Mourning, trans. Corinne Pache (Ithaca and London: Cornell University Press, 1998). Hereafter MM, with the page number. 
“Achilles suggests the example of a mother as a model for Priam's paternal mourning, as if only a mother could really understand pain" (MM, 45). Following Laura Slatkin, she proposes the rather extravagant argument that his menis is a dislocated reinterpretation of the "wrath" of his mother, Thetis, and that "it is necessary to give back to Thetis what makes the Iliad Achilles' poem" (MM, 49). This is also why Loraux, writing about the concept of menis, speaks about "a female model of memory, which the cities try to confine within the anti- (or ante-) political sphere. And in fact, wrath in mourning, the principle of which is eternal repetition, willingly expresses itself with an aei [i.e. with an attribute of perpetuity, again and again, constantly, always], and the fascination with this tireless 'always' threatens to set it up as a powerful rival to the political aei that establishes the memory of institutions" (MM, 98).

As shown by the case of Demeter who, after losing her daughter, blocks nature's mechanisms of biological vegetation, this persistent, mournful wrath is directed at the cosmic order embodied and maintained by Zeus (MM, 4445). This is also a state of self-exclusion from the community, of obstinate endurance, and imprisonment - emblematic in the figure of the petrified Niobe, or the "rock that weeps" (MM, 45). In the context of reversing Klein's perspective as proposed earlier, what is fascinating is Loraux's description of the timeless nature of women's mourning and mournful wrath, invoking the figure of Clytemnestra, the mother of Iphigenia who was sacrificed by her own father, Agamemnon. According to Loraux, the "unmanageable remnant" of the affect of mourning finds its place in theatre (MM,10). This is also why she presents a series of observations pertaining to female mourning from the texts of Attic tragedy, including the figure of Clytemnestra. Loraux writes:

Clytemnestra, in Aeschylus, claims that her hated husband has sacrificed "his child, my dear pain" (philtáten emoi odina). Odis describes the searing pangs of childbirth; designated as odis beyond death, the young daughter Iphigenia incarnates for her mother a life that has barely been detached from her own body and whose loss her mother feels all the more in an instant of sinister repetition of the wrenching of the ultimate separation - as if Clytemnestra could not stop giving birth in endless parturition as long as her daughter lived. (MM, 39)

It is also no surprise that Loraux sees Clytemnestra as the epitome of menis, and demands that she be regarded not so much as an adulteress but as a mother avenging the death of her daughter by killing "the husband who knew not how to be a father" (MM, 50).

For our further considerations, it is worth taking a look at one more issue. Against the backdrop of the relationship sketched between the grieving 
woman, the patriarchal order of the polis, and mournful, threatening wrath, Loraux presents an extremely intriguing historical riddle, and proposes an equally intriguing solution. In the centre of Athens, right on the Agora, there once stood a temple to the mother goddess, the so-called Metroon. Furthermore, the same building was also probably home to the Bouleuterion for some time, where the Council of Athens was seated. Later, when a separate building was opened for the council, but still directly adjacent to the Metroon, the mother temple housed another important institution: the city archive. Thus the mother (at least according to one orator) watched over the whole recorded memory of Athenian democracy. If Loraux is right to point to the conflict between womanhood and Athenian politics, and particularly between the mournful anger of women's memory and memory constitutive of the polis, then there is no doubt that the key role of the mother temple as the site of the city archive and its physical location adjacent to the actual centre of political life demand an explanation. Loraux suggests the following perspective. She examines the Greek (and especially the Aristotelian) view of the mother's function in the process of procreation, in which the mother is a matrix, the wax on which the father, like a writer, impresses his seal; thus in the ideal case, sons should be the perfect reflections of their fathers, without inheriting any additional characteristics from the mother's side. According to Loraux, this particular conviction, along with the analogy connecting impregnation with the writing process, can enable us to solve the Metroon riddle. By placing the city archive - a collection of patriarchal writings and political memory based on the continuity of institutions - in the home of the mother, potentially the source rather of a different memory, of unforgiving, mournful wrath turning against political continuity with all its subversive power, Loraux argues that the Athenians were trying to domesticate the mother, making an imprint on her maternal matrix and, paradoxically, exploiting her wrathful power to protect the laws to which it is essentially opposed. This was how the machinery of justice inscribed in the city's laws was to operate. According to Loraux, however, the city fathers were also aware that the phantom of "another [form of] justice" (MM, 77), the one ascribed to the undomesticated power of wrathful mourning, never ceased to threaten the political order.

Taking this handful of ideas as a constellation of possible reference points, rather than as a theoretical construct to apply, I would like to explore certain elements of Justyna Bargielska's work. ${ }^{5}$ I am interested in something

5 I focus here solely on Bargielska's first three volumes of poetry (Dating Sessions, China Shipping and Dwa fiaty [Two Fiats]), recently collected in one book: Justyna Bargielska, Szybko przez wszystko [Quickly through Everything] (Wrocław: Biuro Literackie, 2013); hereafter SW, with the page number; as well as her prose debut: Justyna Bargielska, 
that (and I admit this is no great discovery) is one of the fundamental topics of her writing - the theme of loss, as well as what Bargielska does in and with the language to record this loss. A decent enough starting point might be the observation that at the level of images, Bargielska very often makes use of various figures of "containers." This poetry and prose is teeming with objects and spaces which either do contain something or have the capacity to do so but remain empty. Were someone to suggest that these containers are a kind of materialisation of the Kleinian-Segalian internal space for storing objects that are good and represent something which we have been separated from, which we have lost, there would be serious reservations in accepting this idea. For starters, Bargielska views loss rather from Hasan-Rokem's and Loraux's perspective, and not from Klein and Segal's, that is from the mother's point of view, not the child's. The original form of the container here is the female womb.

Sometimes, though relatively seldom, this is spoken of solely in the context of an erotic relationship between a woman and a man, without referencing the mother-foetus relationship. This opens up, however, the melancholy interplay between fullness and emptiness, containment and loss - a desolation that must be compensated for by another type of incorporation. In the poem depresyjnie, prawie proza [depressively, almost in prose], for example (SW, 31):

sesame seeds from caramel cake

this morning you filled my belly

but at noon I was empty of you ${ }^{6}$

When the image of the womb is referred to in the context of the motherchild relationship along with images of birth, images of death also generally appear, even when the subject is not explicitly miscarriages or stillbirths, which are overt themes in Obsoletki [Stillbirthlets] and in a number of poems in Dwa fiaty. In the doleful poem pani jeżowa [mrs hedgehog] (SW, 27), the connection between love, pregnancy birth, and death is an enigmatic constellation of images outlined by a man's tongue for a while, before it surrenders to the paleo-suffering of odis, unable to turn the poem into a space for happiness:

Obsoletki [Stillbirthlets] (Wołowiec: Wydawnictwo Czarne, 2010); hereafter O, with the page number.

6 Translator's note: As only some of Justyna Bargielska's poems are so far available in English, unless otherwise indicated, all translations of her work quoted here are mine. A volume of her selected poems entitled The Great Plan B translated by Maria Jastrzębska is due for publication in autumn 2017. 
my wife is crying. it was supposed to be different our life in a poem. translucent little fists

tightening the belly. to bed dragging a stone

lion: I only touch it, and it threatens.

a mouse hangs itself on a watchstrap.

until they play our song: the hit of paleo-beaches, a quadrille

of contracting and relaxing, in which my tongue

embalmed in fossil resins and dull-bitch honeys

sucked out from my wife

happily stops trying to describe it.

In the moving, untitled poem with the incipit "the red one gave birth to kittens when dad was on business" (SW, 36), where a deceptive story of happiness is told with a tender touch of the tongue, and a fragment of amorous discourse is located within the memory of animal birth, the association between birth and death is now entirely clear:

the red one gave birth to kittens when dad was away on business

she licked their mottled skins surprised at how many suns

could burst forth and flow out of a cat it grew

late because of her the skins opened their eyes to the world

the red one's tongue told of it the milky ticking

in a rhythm of unhurried tensing and relaxing attending

enraptured with life they withered and fell away

the skins struggled dad returned to close their eyes

once opened blithely what I mean to say is

you lick the scraps of the darkness off me like dad

he left with a bag mum stroked in me

the memory of how to kill but I remember

how to die after all

Since the link between birth and death is so close in Bargielska's work, it is unsurprising that the image of the womb as a container for children borders with the image of the grave as a container for corpses, and sometimes even overlaps with it. Still without this superposition of images, the connection appears in the poem "moja!" ("mine!") (SW, 10), where the male fantasy of selfsiring and emancipation from the ambivalent, oedipal relationship with the father is replaced by a fantasy of self-birth and -burial, which can be both an analogous dream of absolute autonomy and of ultimate self-evisceration, the final separation from oneself, of the peace and purity of death: 
she decided to

bury herself regrets that she

could not give birth to herself more thoroughly

clean off the muck hollowed full of holes

at times she mistakes herself for an ocarina and opens

the door and windows throw her a ball of light silk scarf

she will think about what a tram can manage

with a penny what am I to her but

one to put on a coat half-turn

and return?

The poem Let's kohelet (SW, 102), with its last line of "Hey, your graves are in me and your dead are here," is a good example of the images of the womb and the tomb being superposed. In Obsoletki, such a superposition appears in a passage in which to the list of containers is added an eerie jar in which the remains of a dead foetus are placed - the narrator states fairly bluntly that "for a while I was a grave" $(0,28)$. It is not surprising that the narrator, commenting upon the title of the song Road to Nowhere, can say: "Death - it is not nowhere. I know that much. I can share that with you" $(0,41)$. No, not nowhere, but in a container.

Sometimes it is not explicitly the women's womb that is spoken about, but only the interior of the more or less corporeal "I." The images of death, however, do not vanish from view. In the poem Jak sobie radziła bez M. [How She Coped without M.] (SW, 19), the speaker wants to "get away from the body as if from a burning car / before it is / too late." In the poem Międzyczasie [Meantime] (SW, 105), the vision of a child being replaced with an animal becomes a figure of loss that is in a way even more terrifying than a direct reference to death; and all this within "you": "you return full of strollers, / passers-by and women whose babies in buggies / somebody has replaced with cats." In Na przyktad Abraham [For Example Abraham] (SW, 47) the "I" becomes a container for the last illusion of life which would make possible a meaningful farewell:

and in the end are cartoons in Gothic font, proclaiming that in the fire the driest woodchip takes on signs of life. Hence the custom of burning corpses: so that they can still wave to us.

And so since they have been carting that wood, they have been carting it in me.

To this image of filling the female body with inanimate objects, we can also add two grotesque visions from Obsoletki: the image of a bottle in the shape 
of the Virgin Mary, which, taken to the swimming pool by the daughter of the narrator-protagonist is "fine until the moment when it lost its crown and water poured inside" $(\mathrm{O}, 33)$; a doll into which the narrator's brother inserts a sausage sandwich, having first removed from the toy its ersatz life - its "walking-talking mechanism" $(\mathrm{O}, 34)$.

The womb, the female body, and the grave are therefore containers for something that will inevitably be or already has been lost. Bargielska's texts abound with other objects, which - all inanimate - also function as containers for death. There is a black bag for the body of a woman killed in a car accident $(\mathrm{O}, 56)$. There is a green crate of a certain transport company that brings misfortune, which is why it is worth ordering the smaller version as part of the "homeopathy of misfortune" $(\mathrm{O}, 75)$. There is a box for the son's umbilical cord, already containing "the bread crust that mum ate while sitting by the dying grandfather" $(\mathrm{O}, 77)$. Finally - or "simply," as one is tempted to say there is a hospital refrigerator overflowing with the remains of dead newborns $(\mathrm{O}, 78)$. This set of images is expanded by more ambiguous and thus perhaps more interesting images from poems. In Czymógłby mi pan pomóc pogasić światta [Could You Help Me Turn Out the Lights, Sir] (SW, 58), a dream about the apocalyptic shattering of the home container evokes the image of a Mexican piñata smashed open with a stick:

Twenty-seven years with a corpse under the floor may not exactly be fifty, but still, hey there, comet! you're here at last, now fuck up the shack, my mexican house with ant piñatas.

In walc na cztery czwarte [waltz in four-four] (SW, 30), the scraps of animal remains become locked houses full of corpses. And perhaps this is the way Bargielska thinks of all objects: "and how scared I am / when the neighbour's pounding pork chops (they won't open, they're dead)." Or finally, the image of a dead dog - neither person nor thing - which could be a suitable container for the remains of the whole world. In Trauma o piesku [Trauma about a Little Dog] (SW, 56):

But it really scared me,

the little dog's duel with a tram, when my husband said: don't look, and behind the hand's card the little dog got up; it was so huge and invited us all into its torn-open belly, in which a priest was waiting, bare trees and a city made of sand. 
In this enumeration, however, I have left out one image of a container whose evocative power makes it seem worth singling out. It comes from the poem Hale Faelbetu (SW, 74):

Or a peep show: how is it

possible that in this booth the second

and subsequent losses of everything are found? Could

parallel worlds or clever use of

mirrors explain it? And where do they go to work?

I do not think that this is just another image that can be placed on equal footing with others. A peep show, a strange booth, in which one can peek at all losses, of everything, captured in an unending trick of mirrors, seems to be a figure of another order: it is a self-referential model of Bargielska's own work referring not to the world of things, but to that of words, referring to a layer of language that tries to accommodate loss. What is decisive is that Bargielska also treats language itself like a container for loss. Along these lines I would read the final section of Kukanie [Cuckoo] (SW, 120), where the poem is asked to say something about an unnamed loss, and this request alone is enough to force it to speak, to accommodate the loss:

Dear poem, say something, say how many children I have, which casts a deeper shadow, and how long I will live with this.

This is also how I would read the sarcastic passage from Obsoletki in which a common figure of speech allows a further container to enter the fray. The narrator says:

I wrote better about things when I didn't know them because I wrote from my head. I wrote, for example, a beautiful poem about miscarriage, and only afterwards did I have a miscarriage. I wrote, for example, a number of sentences justifying why it's worth taking photos of dead babies, and only afterwards did I start taking such photos myself. $(0,65)$

Writing "from one's head," that is using a container known as one's head, means writing beautifully and profusely, the language being filled with everything that is housed in the head. New writing demands the opposite operation. The gaping emptiness of physical loss now needs to be introduced into language; language itself must be eviscerated, becoming a booth for loss. 
We might call this operation of transmitting loss to language a translation. The wonderful poem, in fact entitled Przektad [Translation] (SW, 127) has many levels, and activates a complicated dynamic between various types of containers, but in the final reckoning it seems to be talking about the fundamental operation of making space in language. The whole poem reads as follows:

From the street I see through the window my mum standing at the sink in the burning house, herself burning for a while, there's not much left of her, in fact only the shape. Thirty years will pass and my daughter will look through the window from the street and see me burning in a burning house. I don't know whether she'll even know what she's looking at.

I made room for death in my life, pulled back the quilt, my shirt, I opened my rib cage. I wouldn't have room for any of you if I hadn't made room for death. Until I made room for death I had no room for any of you - don't fool yourselves. I open a nut and find a mouse's ashes, my husband and children, my reward, my confirmation.

At the level of images, we have three containers: the house, the body, and a nutshell. "Those that are invisible can't be seen in others' windows," says the narrator of Obsoletki $(\mathrm{O}, 78)$. In Translation somebody (the mother of the speaker) is still visible in the container of her own house, but she is burning along with it. The imagined transformation of what is observed also depicts the speaker inside the burning home, observed by her daughter (perhaps this transposition is a kind of translation). The mothers burn, shut inside their homes. Is this because we are increasingly deprived of them, and we can only watch them fading away, no longer promising to return us to the narcissistic peace of earlier times, and today more akin to children? Alternatively, is it because they themselves inevitably lose something, gradually disappearing while giving up parts of themselves again and again in the unfinished process of giving birth, while we, without quite knowing what we are looking at, can only watch them from the outside as they dwindle, imprisoned in the houses of their bodies?

The answer is probably a bit of both. In any case, the speaker herself becomes a container and lets death inside her body. A strange container and a strange, unique thing is filling it: only when it is let in, is there room for other people. Only then can we open the next container, a nutshell hiding the reward - the whole family - but always next to the ashes of a mouse, 
no doubt the same one that hanged itself from a watchstrap, accompanied by Mrs hedgehog's heart-rending weeping. So what about making room for death? In the simplest sense, perhaps this means that only by letting death into our lives, accepting loss, we stop filling our whole world with ourselves; only then can we make space for others. In the nutshell we would find only ourselves, and not our loved ones, if we did not also find the mouse's ashes. Perhaps. But that is not all: the poem is called Translation. The poem is itself the fourth container into which loss is translated - not from the head, but from the world. Perhaps only the translation of loss into language prevents loss itself from filling our whole lives with its dark mass: perhaps only making room for death in such a way leaves space for others, and the nutshell can only be opened in the poem.

I am not sure. However, this kind of translation is certainly taking place here. It is what causes the language to become pockmarked, but it is also only thanks to this translation that language regains its dignity time and again. Just as lamentation, which between the lines asks about the enigma of loss, creates a breach in the arithmetic of retribution and the excessively efficient mechanisms of theodicy (according to Galit Hasan-Rokem), and just as the mournful, unforgiving, ever returning wrath of mothers tears apart the continuity of legal-political discourse, bringing to the fray "another justice" that speaks up for the individuality of the lost (according to Nicole Loraux), Bargielska too, in making this translation of loss, pierces, punctures, and guts excessively compact language with irony, making it a container for loss, creating in it a place for non-erasable, wrathful memory, imbuing speech with mournful lament, which prevents it from being a frozen lump and makes it once again able, once again authorised, to resound. Only language that has made space within itself for loss can speak about what is not lost.

Let us look at three less obvious examples of such a translation in Obsoletki. The first passage from the book entitled "I'd like to tell you about the last time I gave birth"7 is full of Anglicisms. For example, there is the line: "And that was the precise moment when I fell in love with him" $(0,8)$. (The original copies blindly the English phrase "the precise moment" which in Polish sounds highly awkward.) This can be interpreted as showing a middle-class woman - a Varsovian filled with memories from her grandmother's village - trying to describe her most intimate experiences using linguistic clichés and Anglicisms which, in their comic clumsiness, only serve to emphasise the nontransmissibility of her experience. These lame phrases, however, also seem to have another function. It is in fact their linguistic awkwardness that makes

7 This passage was translated by David French, available at http://www.bookinstitute.pl/ ksiazki-detal,literatura-polska,6731,stillbirthlet.html/, accessed March 24, 2017. 
them more susceptible to fissure and dialecticall transformation into a container for loss, into a peep show. Here is a particularly successful example of this mechanism: "We dropped off our child at the childminder's on the way" $(\mathrm{O}, 7)$. Nominally this is about the narrator and her husband going to give birth and therefore leaving their older child with the babysitter. However, Bargielska uses an ugly Anglicism in choosing the word upuścić as a direct translation of the English "drop off," thereby ironically opening the text to the horror of miscarriage and loss; and thus signposting the main subject of the book on its first page. This horror is confined to the linguistic level as nothing bad happens at the level of the story: the child is born healthy, and death - that is "dropping" - only appears in the last sentence of the passage, displaced: "Next time, I'd like to tell you about my cat Pawel's fatal fall from the balcony" $(\mathrm{O}, 8)$.

The second example in which the language is once again stretched to make space for loss is based not so much on a linguistic error, as on the flicker of a hackneyed phrase. The narrator-protagonist heads off to the cemetery, pushing her baby in a buggy, with her mother in tow, to "clean the graves." She asks her mother where she and father would like to be buried, and notes down the response of her mother who looks concerned." «Are you writing a poem?» asked Mum. «I don't know how you can write those poems. Who you take after»." The narrator-protagonist says to herself: "Maybe Dad" (O, 13). And again, nominally, nothing special is happening here, except, perhaps, that something that was to be a poem is in fact a note on the possibility of "adding" one's parents to the graves of previously deceased family members. The poem is therefore literally replaced with a list of containers for dead bodies. In the words of the mother, though, and her daughter's unspoken answer, something else seems to resonate. Perhaps in the phrase "take after someone" with her talent for writing [pisać po kims], we should hear echoes of the phrase "cry over someone" [ptakać po kims']. Perhaps, then, it is as much about somebody (the father?) who is the genetic source of the narrator's writing talent, as about somebody (the father? mother? children?) whose actual, or so far only potential, absence is to be represented in writing: and it is in this "precise moment," in this ironic bipolarity and loosening of the phrase, that it is actually represented.

Finally, the third example is based on the extraordinary possibilities concealed in a stock newspaper phrase. In the passage titled “But why doesn't Dad sleep in Mum's room," the members of the family talk about various matters, jumping pell-mell from subject to subject. The weighty issue that is raised is that of quilts, which "get dirty from disuse," even when kept in a bag (again a container), because they need to "regularly feel a human body under them"; otherwise they "grow mouldy." At this point of the exchange, seemingly innocent but already reeking of a grave, the narrator-protagonist makes a sudden 
leap and asks perhaps a cousin, a quilt expert, or a sister who has experienced miscarriage: "Speaking of getting mouldy - I remembered - they took a photo of your belly for the paper, but they captioned it «Archive». You ain't angry, are you?" $(0,64)$. Many things have been squeezed into the dark ironies of this sentence. Through this otherwise standard caption, the newspaper discourse pushes into anonymity both the woman presented in the photograph (along with her suffering) and the one who took the picture. But if we treat the caption not so much as an indication (or erasure thereof) of the source and author of the photo, but rather as its title, the woman's stomach here becomes an archive in the most dramatic sense: an archive of dead foetuses. So perhaps it is again saying: you have no name and are only an archive of obsolete things, just another stillbirthlet. Nonetheless, "archive," as the title of the photograph, can also mean something else of course, such as the place where the pain of loss in its entirety is really archived. Ultimately, therefore, the sister (if she is the addressee of the narrator-protagonist's words) should not be "angry," because her anger, menis, itself comes out in the fracturing, ironically splitting word. If Loraux showed that the location of the Athenian archive - a container for the city's institutional memory - in the temple of the mother goddess was meant to tame the force of women's mourning, perpetually posing a threat to legal-political continuity, in Bargielska's text, the word "archive" becomes a double agent: on the one hand, it does indeed erase a woman's name, but on the other hand (contrary to those who made use of it) it brings to light women's loss and becomes the name of a great container of wrathful counter-memory.

The last example sends us to a certain fundamental question that we have not yet touched upon. The narrator-protagonist of Obsoletki takes photographs of stillborn foetuses, before processing them on the computer (computer memory? another container?) and forwarding them to parents, even if in the photos one can often only see something like a "little liver" $(0,39)$. These photographs seem to fulfil a key function in the economy of the text. For, ultimately, what does it mean to make room for loss in language? What does it mean to transform a poem into a peep show, into a booth in which one can see something? Is the linguistic container to hold what is lost, or the emptiness that results from this something or someone, this someone as lost? But what does this look like? What is the linguistic and ontological status of this unique content? Perhaps the photos of dead foetuses - although not the photographs per se but their ekphrastic representation in the text with the images emerging from language - are the strange things that need to be placed in storage; perhaps they are what can be seen in this peep show, and it is they that elude the opposition between what is lost and the absence of what is lost, and it is they that, as a visual remnant, mark this acute absence. 
Justyna Bargielska's lamentations are ironic lamentations. Their irony does not neutralize the pathos exposing language to suffering, but is itself a tool of the subtle tears that make room for loss in language. And in the centre of these lamentations stand the images appearing in language which complement stop, and stitch the ironic play of the text and allow loss to be seen in its absolute singularity.

These ironic, textual-photographic lamentations also have a barely sketched, but important theological dimension. We observe here an outline of a heretical theology that we could (only partially in jest) call "Marian anti-Paulinism." Indeed, Paul of Tarsus gets flake at least twice. First, in the conclusion of the poem Gringo (SW, 122), Bargielska writes: "O death, unpronounceable, touching young lady. / Wherever is your victory? I'll show you myself." The rhetorical question answered with such a foolishly obliging proposal radically changes its meaning, and the hymn about the theologically decreed mechanisms of the resurrection is transformed into a fragmentary, sarcastic lament championing the manifestly dead. The second blow is aimed at the apostle in the passage from Obsoletki, referred to previously, which mentions the ghostly jar that Bargielska could point to without hesitation if she were to help death seek out victory. The excerpt begins with a paragraph filled with another brief quotation from the Letter to the Corinthians, adjusted in Polish to use feminine forms for the first person singular: "When I was a child, I spoke like a child." This sentence heralds a childhood story about burying a pigeon, told in a brief paragraph. The next paragraph is again a single sentence, which really shows off Bargielska's sarcasm (still using feminine forms for the first person singular): "When I became a man, I gave up childish ways" $(0,27)$. Immediately afterwards comes a story about a miscarriage, which mercilessly exposes the grotesque chasm between Paul's discourse and women's experience of loss.

As stated, however, this anti-Paulinism is Marian in character: Bargielska plays off against Paul the figure of the Virgin Mary, with a curious version of the latter whom her heroine identifies with. We have already come across the bottle in the shape of the Virgin Mary where "water was poured inside." Meanwhile, in a dream the narrator-protagonist imagines that she is fighting evil as Mary's deputy, but one who needs to stay in constant touch with the central Mother. Here the author paints another vision of the woman's body as container:

Furthermore, being in constant touch with the Mother of God, the commander-in-chief, could also be tiring. Sometimes I'd feel like the reputed lady who called the radio to ask if it is possible to do a transplant remotely because she felt she was losing organs. $(\mathrm{O}, 37)$ 
The next passage, discussing photographing dead babies - similar in appearance to livers - finishes with a subsequent record of the protagonist's dream with the Virgin Mary in the main role:

In the night I dream that on the eighth day they bring the Lord Jesus to the temple. The Virgin Mary unwraps the cloth and unwraps, and unwraps. "Whoa," says the Virgin Mary. She takes off more layers, and the cloths become ever whiter. She unwraps, until it stops, but I don't know what she finds in the whitest cloth, because she's in my way, bending over it. “That wasn't the plan," she says. $(0,40)$

The figure of Jesus altered, perhaps, into a little liver, radicalises this heretical, sarcastic Marian theology to the extent that the Virgin Mary liberates herself from her function as intermediary en route to the men of her life, a function that she fulfils in Catholic theology, and as mother of a divine, but dead, liver (how's that for a version of the doctrine of the Incarnation!) becomes the source of an endless, wrathful grievance tearing apart the text concerning the ideology of the resurrection.

It is also in this spirit that I would read the conclusion to Obsoletki, which at first glance smacks of a somewhat infantile narcissism. The last section of the book again begins with a biblical quotation: "Before I formed you in the womb I knew you (Jeremiah 1: 5)," and ends with an apocryphal quotation: "No, I do not know you. I formed myself (Justyna $1, \infty)$ " (0, 87). God the Father knows his prophet (the very one who is credited with being the author of the Book of Lamentations) even in the mother's womb, before he has even formed him. He reaches for him there, as he would, without asking, to inspire him with a prophetic word, which Jeremiah, like it or not, must pass on. In this function, God - the aggressive father who at times beats his son to death and then does not know what to do - is a great phallus who passes on to poor Jeremiah the transfer of inspiration. Bargielska, however, knows another meaning to this touch. In the poem Radyjko [Little Radio] (SW, 119), she writes:

Unrestrained divisor, with that rough paw

from the newborns section I don't know if I want

you to touch me. I'm telling you, really.

This is why she juxtaposes the biblical quotation with her apocrypha. The old regret of not having given birth to herself more thoroughly, and the consequent decision to bury herself by her own hand, is now transformed into a wrathful statement of facts. Is this a declaration of absolute autonomy, of the independence of primal narcissism? I do not think so. If anything, it is an 
expression of refusal to participate in the male game of transfer of prophetic inspiration - I do not know you, I do not want to know you and I do not want to be known by you, especially in the biblical sense - as well as a refusal to accept the grand systems of theodicy moving to the order of things which we did not sign up for. The sign of infinity in the bibliographical reference is, therefore, not a sign of narcissistic self-deification, but rather of indefinite lingering in the position of mournful, persistent counter-memory, which holds on to its loss, torn by eternal menis.

By its very nature, though, this literary theology also inevitably turns it into an anti-theology. Bargielska's dirges, no matter how explosive and dangerous they potentially are for various orders of discourse, in their very nature remain something extremely intimate. This is why the peep show ultimately closes up, as the poem Jednym stowem [In a Word] $(\mathrm{SW}, 121)^{\mathbf{8}}$ says:

I'm asking if they've sent off that goddamn corpse or not. They write me that they have, the delay might have been due to the weather and that I should drop them a line next Wednesday whether I was going to complain or if I wanted another corpse instead. I don't really know, I have time till Wednesday to think this over. A worm betrayed another worm and now it writhes, both in dreams, and everywhere. Whereas in the light from the school's library windows it seems that my child's turned into stone and it says: don't cry, woman, if I'm not crying. Come on, close up, nothin' to see here, nothin' to see.

Translation: Benjamin Koschalka

8 Poem translated by Katarzyna Szuster. Available at http://www.versopolis.com/poet/53/ justyna-bargielska/poem/607/jednym-sowem, accessed March 24, 2017. 